IRA-International Journal of Management \& Social Sciences

ISSN 2455-2267; Vol.03, Issue 03 (2016)

Institute of Research Advances

http://research-advances.org/index.php/RAJMSS

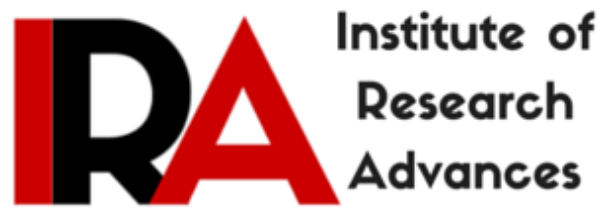

\title{
Cultural Beliefs and Practices of Ethnic Filipinos: An Ethnographic Study
}

\section{Evelyn J. Grey, Ph. D.}

West Visayas State University

Iloilo City, Philippines.

DOI: http://dx.doi.org/10.21013/jmss.v3.n3.p30

\section{How to cite this paper:}

Grey, E. (2016). Cultural Beliefs and Practices of Ethnic Filipinos: An Ethnographic Study. IRA-International Journal of Management \& Social Sciences (ISSN 2455-2267), 3(3). doi:http://dx.doi.org/10.21013/jmss.v3.n3.p30

(C) Institute of Research Advances

(cc) EY-NC

This works is licensed under a Creative Commons Attribution-Non Commercial 4.0 International License subject to proper citation to the publication source of the work.

Disclaimer: The scholarly papers as reviewed and published by the Institute of Research Advances (IRA) are the views and opinions of their respective authors and are not the views or opinions of the IRA. The IRA disclaims of any harm or loss caused due to the published content to any party. 
ABSTRACT

The study was to determine the cultural beliefs and practices of the ethnic Filipinos. This is a qualitative study and the focus is the Aetas living in Central Philippines. The informants were the 9 prominent Aetas, 6 of them were Aeta women who have experienced pregnancy or pregnant during the time this study was conducted. The findings revealed that during pregnancy their most beliefs and practices are observed by the Aetas. Some of the traditional beliefs and practices of Aetas have been influenced by many factors. They have also retained some of their traditional beliefs and practices on pregnancy, childbirth, marriage, death and burial despite the effects of the factors mentioned. All throughout the life stages of the Aetas in the rural communities, their old beliefs and practices had been influenced by modernization. It simply shows that the Aetas, are also susceptible to accept changes that may affect their way of life. Their traditional cultural practices that deeply rooted in their beliefs were difficult to neglect since it has already been part of their tradition for years.

Keywords: Aetas, beliefs, ethnic Filipinos, practices, ethnographic

The Aetas, as the aboriginal inhabitants of the archipelago, are scattered all over the Philippines. Their community, once called a village, is now a barrio or barangay as a result of colonization and improved civilization. The Aetas were nomadic, living in the hunting and gathering society. Normally, males went to the mountains where they would hunt wild animals while females gathered wild fruits, root crops, and vegetables for their food. However, this mode of living gradually changed with time. They were rich in their indigenous knowledge and practices that sustained their communities long before the coming of other cultures (Panes and Aguibiador, 2008). They are now influenced by different environmental factors that affect their need for health care.

This study intended to examine the health care beliefs and practices accompanying the life cycles of Aetas in the rural communities. Likewise, it examined the factors affecting their health care beliefs and practices through time.

Along this line, the researchers believe that a better understanding of the various health care beliefs and practices of the Aetas in the rural communities is necessary. These would show the direction of help which may be given to the Aetas in the rural communities.

\section{Related Literature}

\section{Beliefs and Practices Among Ethnic Groups}

The succeeding discussions will present the beliefs and practices of the various ethnic groups in other parts of the Philippines particularly the Northern part of Luzon.

Bontok. In Bontok society, a marriage is fully consummated only after the birth of the child. The man usually takes pride in having a successor who shall continue his lineage. The pregnant woman, while being careful not to lose her baby, continues her daily work routine until the baby is delivered, which can even happen in the field itself. She observes taboos to avoid miscarriage or any other misfortune that may befall her and the unborn child. Custom dictates that the conceiving woman and her husband must not travel to far places where envious spirits may cause harm to the unborn child. They are also prohibited from going near springs and other natural outlets of the earth, believed to 
be the residence of the spirits. For the woman, she is not allowed to take a bath at sunrise so she shall not give birth to an albino; and in going to the fields, she is cautioned not to go alone at 10 o'clock in the morning or 12 o'clock high noon so as not to invite the envious eyes of the spirit (anito) along her path and cause her to lose her unborn child. Also, the pregnant woman must never sleep near open windows or openings of the house to avoid a kind of bird that is believed to prey on the hearts of the unborn and newborn babies (Cordillera Schools Group, 2003).

Ifugao. As an Ifugao is developing in his mother's womb, a pregnancy ritual called pahang is performed for the safety of the mother and for normal pregnancy. It is followed by another ritual called palat di oban to ensure normal birth and delivery. This is done a few days before a woman gives birth and delivery (Ethnography of the Major Ethnolinguistic Groups in Cordillera, 2003).

Apayao. When a woman is pregnant, she observes certain taboos to ensure her welfare and that of her child. She is discouraged from eating certain types of sugarcane and banana, and she is not permitted to eat the soft meat of a sprouting coconut so she shall not experience difficulty in giving birth. In some places, it is also taboo for visitors to sit or stand on the ladder or for rice ladles to be left inside the rice pot. However, these taboos are not universally observed in all of Apayao. Taboos vary from place to place (Ethnography of the Major Ethnolinguistic Groups in Cordillera, 2003).

Isneg. A pregnant Isneg woman continues her daily chores, including pounding of rice and working in the farm. Sometimes, it is in the farm where the woman gives birth.

Female relatives attend to a woman during childbirth (Ethnography of the Major Ethnolinguistic Groups in Cordillera, 2003).

Kalinga. Children are greatly desired among the Kalingas such that when a husband and wife are not able to bear a child, they divorce each other. On the other hand, if pregnancy occurs, the husband and wife are subject to customary rituals and restrictions to ensure the safety of the unborn child and of the whole household.

Among the Kalingas of Tabuk, the pregnant mother is prohibited from eating twin bananas, wild berry(pinit), wild honey, unhatched egg(uk-bong or balut), carabao meat, meat of a wild boar, and many others. These are believed to cause childbirth defects (Ethnography of the Major Ethnolinguistic Groups in Cordillera, 2003).

In Poswoy, a pregnant woman and her husband are prohibited from eating certain foods like beef, cow's milk, and dog meat. They also must avoid the ngilin, the evil water spirit that is said to reside in streams and waterfalls, and cause harm to the unborn child. Both should also carry with them either a dog or a crocodile tooth or a piece of bark (sugaga) to protect them from the malevolent spirit when they happen to pass by near its residence. Pregnant women are not allowed to sit by doors or windows so that the unborn child shall not be born in breach position. The father also avoids playing the flute lest the infant becomes an incessant crybaby (Ethnography of the Major Ethnolinguistic Groups in Cordillera, 2003).

Northern Kankana-eys. Among the Northern Kankana-eys, the conception of a child places restrictions on the activities of both husband and wife to ensure the welfare of the mother and the child. The man is not allowed to cut down trees or build stonewalls 
so as not to complicate delivery. Both husband and wife are forbidden to approach the house of cave-dwelling spirits (nginin) who are believed to take the souls of children but not of adults (Barton; in Scott, 1988). However, because of the need to work to feed one's family, a pregnant woman is obliged to work. Sometimes a baby can be born in the field or along the way because of this (Ethnography of the Major Ethnolinguistic Groups in Cordillera, 2003).

Similarly, among the Mankayan Kankana-eys, both husband and wife are put under a period of restriction from conception until the birth of the child. The pregnant woman is not allowed to eat certain foods such as an unhatched egg (balut) and twin bananas as these are believed to cause deformities in the unborn child. She avoids doing heavy work and refrains from passing by caves, streams, and other places where evil spirits may harm the child. The father does more of the heavier tasks and avoids going on a journey where evil spirits may cast harm on the child through him (Bello, 1972). A few weeks before the expected delivery, a small pig or a chicken is butchered and sacrificed, after which the bile is inspected for omens (Ethnography of the Major Ethnolinguistic Groups in Cordillera, 2003).

Tingguians. From the moment of conception, the Tingguians believe that supernatural beings are involved in the whole process of pregnancy and childbirth. Thus, unnatural births are usually attributed to supernatural beings. When a woman is conceiving, it is believed that a spirit (anito) gets pregnant at the same time, and that both mother and spirit deliver their babies at the same time (Ethnography of the Major Ethnolinguistic Groups in Cordillera, 2003).

Several taboos have to be observed by the pregnant woman to ensure safety of the child. She is prohibited from eating certain foods like twin bananas or vegetables for these foods are believed to result in the birth of twins. Towards the latter part of her pregnancy, a ritual is performed by a medium who offers rice and a pig to the spirits. The ritual is done to "make the delivery easier" and to predict the future of the child from the position of the liver of the sacrificed pig (Ethnography of the Major Ethnolinguistic Groups in Cordillera, 2003).

\section{Aetas}

Aetas or Negritoes are the aborigines of the Philippines who were called Negritos by the Spaniards at the time of their reign in the Philippines because of the former's darker skin color. It is the tribe inhabiting the eastern rural community of Luzon and other parts of the Philippines. They are called in different names: Agta, Ita, Aeta, or Ati. As a result of their nomadic life, they live in houses built out of grass and tree branches to easily vacate upon scarcity of surrounding food. They do not have social rules and live according to their ancient customs, which are most evidently shown in the way they dress.

According to Seitz (2005), Aeta forms part of the Philippines' aboriginal population, the so-called Negritoes. The Negritoes differ from other Filipino groups in their racial phenotype, characterized by curly hair, dark complexion and small stature, and by their lifestyle strongly focused on foraging strategies. As the remnants of an ancient pre-Mongoloid population of Southeast Asia, small groups of Negritoes have survived only on the Andamans in western Malaysia and on some of the larger Philippine islands. 
Several ethnonyms are commonly used in reference to the Negrito population of the Philippines. The Negritoes of Mt. Pinatubo are specifically called Aeta by their neigbors. They frequently speak of themselves as Aeta, but many also employ the designation "Tumandok", meaning "the ones from this land".

As an ethnic cultural minority, the Aeta have been driven into a socially, politically, and economically disadvantageous position vis a vis the dominant lowland populations. The process has been intensified by the isolation of their upland habitat and by a lifestyle much unlike that of the lowlands. There are also racial differences between the lowland group and the Aeta which play a substantial role in the marginalization of the latter. Thus, all criteria usually used to define marginal groups generally apply to the Aeta who have never really been accepted as equal partners in the development of the place. On the contrary, the sociopolitical indifference the Aeta had experienced before the disaster was augmented by a decidedly socioeconomic dimension after the eruption of Mt. Pinatubo.

One theory suggests that the Aeta are the descendants of the original inhabitants of the Philippines who arrived through land bridges that linked the country with the Asian mainland some 30,000 years ago. They lived in the lowlands but gradually retreated into the hills and mountains when subsequent immigrants and conquerors, like the Spaniards, pushed them into the forests. While resisting change from the outside for hundreds of years, the Aeta have adjusted to social, economic, cultural, and political pressures with remarkable resilience. They have created systems and structures within their culture to cushion the sudden impact of change (Wee, No Date).

Their distinguishing features are shorter stature, darker skin, and curly hair. Their strong adaptation to tropical jungles made them comparable with the pygmies in the equatorial jungles of Africa.

Aetas believe in supreme beings who rule over minor spirits. They believe that these spirits are the inhabitants of rivers, sky, mountains, valleys and other places. Some of their dances are performed to apologize for their catch and to inspire their future hunt. The Aeta are naturally skilled in weaving and planting and they produce excellent winnowing baskets, rattan hammocks, and other household containers. Their traditional clothing adapts to their simple life. Young women wear wraparound skirts, elder women wear bark cloth, while elder men cover themselves with loincloths. The old women of the Agta group wear their bark cloth strip which passes between legs, and is attached to a string around the waist. Decorative disfigurement is a traditional art most Aeta groups practice to decorate their bodies. Scarification or intentionally wounding the skin to form a scar is a common visual art.

Several groups of Aeta have been recorded present in many parts of the archipelago. In Ilocos, they are called Pugot or pugut, a name designated by Ilocanos for anyone with dark skin. In their dialect, it also means "goblin" or "forest spirit". In some areas of Mindanao, groups of Aeta are called Dumagat and in Bicol Region, they are named Agta. In Iloilo, they are called Aeta (Catseye, 2004). 


\section{Purpose of the Study}

\section{Methodology}

The purpose of this study is to determine the health care beliefs and practices of the Aetas in the rural communities. Likewise, this study aimed to determine the factors that may have affected these health care beliefs and practices of the Aetas.

\section{Participants, Sampling and Setting}

The participants of this study are the 9 prominent Aetas, 6 of them were Aeta women who have experienced pregnancy or pregnant during the time this study was conducted. Purposive sampling was used to identify the informants of the study. It is a form of sampling in which the selection of the sample is based on the judgment of the researcher based on the criteria set in the study. The researchers chose Aetas who had met these criteria to be the informants of this study. The criteria were as follows: must be a resident of the Aeta community in one barangay in the central part of Panay, must be an Aeta and must have an influential role in the community.

They are purposively chosen from among the Aetas living in one barangay in the Central part of Panay.

\section{Research Design}

This study is a qualitative research employing a descriptive and ethnographic research design using the non-participant observation, interview and documentary as methods. According to Schumacher (2005), the qualitative the specific procedures are identified during the research rather than specified ahead of time. In an ethnographic study, the research relies on observation, interviewing, and document analysis, or a combination of these, to provide an in-depth understanding of what is studied. It begins with the planning phase, in which general research questions, the kind of site, and types of participants needed are identified (Schumacher, 2005).

Non-participant observation is a data collection method used extensively in case study research in which the researcher enters a social system to observe events, activities, and interactions with the aim of gaining a direct understanding of a phenomenon in its natural context (Liu \& Maitlis, 2010); while ethnographic interview is often the unstructured or in-depth interview wherein the interviewer use a general interview guide but not a set of specific questions worded precisely the same for every interviewee. On the other hand, are records or publications regarding on something, may it be a culture of the group of people or anything else (Schumacher, 2005).

\section{Data Collection}

The researchers sought and obtained permission from the proper authorities to conduct the study. The authorities such as the Director of the National Commission of Indigenous People, Region 6 Western Visayas.

This study focused on the health care beliefs and practices of Aetas in rural communities. In order to understand these beliefs and practices of Aeta, the researchers conducted the study in several stages, as follows:

Stage 1: Preliminary visit among the Aeta and identification of informants

As soon as permission was obtained, the researchers set the date to go to a rural community in Brgy. Matag-ub for preliminary visit and identification of possible informants. The informants of this study were selected from among the Aeta women in 
Brgy. Matag-ub, Janiuay, Iloilo, by following on the criteria set. Likewise, the researchers asked for the assistance of the Barangay Captain and tribal leader to acquaint them on the Aetas and to ask their permission to be the informants in the study. A preliminary observation and a tape recorded interview were conducted after their approval.

Stage 2: Noting significant details on the health care beliefs and practices of the Aetas

The researchers listened to the tape recorded interview of the subjects and they noted significant details related to the topic. Discussions among the researchers were done and data were compared between informants to determine similarities between descriptions and also to identify areas that would need clarification.

Stage 3 Conducting interviews focusing on the health care beliefs and practices

After determining the important points to be considered, the researchers returned to Barangay Matag-ub Janiuay, Iloilo, to conduct in-depth interviews about the Aeta's usual practices towards health care. The Aeta women were interviewed regarding their personal health care beliefs and practices.

Stage 4: Collecting data from other sources

After the observations and interviews made by the researchers, documents that reflected the health care of Aetas in the rural communities were examined. At the same time, the researchers gathered information through documents related to health care among indigenous people.

\section{Data Analysis Procedure}

The analysis in this study involved four phases, namely; (1) The researchers collected, documented, and described the data taken from the informants; (2) The researchers transcribed the data gathered through interview; (3) The researchers identified the significant details and categorized descriptors and components. Repeated descriptions were noted and patterns of beliefs and practices of the Aetas with regards to health care were identified; and (4) Major themes were identified and were compared to the etic views and descriptions of health care.

\section{Results and Discussions}

The results of this study and its discussion is presented by stage in the human life cycle of the Aetas. Such stages are presented below:

\section{Pregnancy}

Pregnancy among Aetas does not vary compared to non Aeta but variations may be in terms of health care. The health care beliefs and practices of these Aetas in the rural communities are as follows:

Aetas also experience craving for something which they term as "pagpanamkon". When this condition occurs, it is important to give what the conceiving woman desires so that the appearance of the child would not be affected or worse, the denial may lead to miscarriage. As much as possible, the people around her, especially the family members, would try to please the pregnant woman to avoid the possibility of her getting angry. 
Aeta women wear a piece of cloth (Bigkis) .They believe that by wearing it, blood could be prevented from rising towards the heart. This is worn all the time. It should not be too loose to prevent "bughat" which according to them, is caused by air rising up towards the head. A month after giving birth, the Aeta woman's "bigkis" may be removed.

Pregnant Aetas wear the "patadyong" for the purpose of preventing their abdomen from getting bigger. They should avoid fondness of religious saints so that the baby will not grow as small as the saint. They are also prohibited to pass over the body of their husband while sleeping in order not to experience difficult delivery. At the same time, pregnant Aeta woman is not allowed to pass over a piece of rope to avoid difficult delivery.

Pregnant Aeta woman believe in the presence of Aswang. As a result, they make use of "labigan"(locally herb) and "kusol" (locally grown herb) to ward them off. Actions like squatting and sitting at the doorway for a pregnant Aeta (during pregnancy) is not allowed for such action would have bad effects to the baby.

They also believe in chants. The most common is "tuyaw" (the term used when one greets another and unconsciously inflicts illness to another) or "usog" (the dialect term for the chant). These are said to cause pain in one's stomach that may lead to vomiting or even worse, death. Placing a towel on the shoulders during pregnancy is not allowed to avoid difficult delivery. Pregnant Aeta women are advised not to peep in the coffin because the baby inside the womb may die. They are prohibited by the elders to go out at night because it is bad for the baby.

If pregnant woman is sick, they utilize herbal medicines such as: a combination of buyo (betel leaf), tabako (tobacco), bunga (betel nut sap), and slightly soaked apog (lime) applied on the stomach for stomach ache/dyspepsia.

The leaves of "istiwitis" could be placed on the forehead to relieve headache and fever. While, the slightly heated (gina-ang) onion leaves together with vapor rub are applied on the back for common colds. They also make use papaya leaves by placing on the forehead to cure typhoid fever. The Banana leaves could be placed on the head or stomach to relieve headache and stomachache.

Sex during pregnancy may put them at risk for Urinary Tract Infection. If UTI occurs, they make use of the roots of the guyabano tree by chopping them into small pieces, and then boiled until most of the juice is extracted from the roots and mixed with the water. Smoking and drinking of alcoholic drinks are prohibited in the entire duration of pregnant. Aeta would also consult the rural health midwife with regards to their pregnancy.

\section{Child Birth}

Like other women, the aeta women have some health care beliefs and practices during childbirth as follows:

Mother Aeta wrapped the baby's body in cloth and takes care of him/her until the midwife or in her absence the hilot arrives. Boiled leaves of plants are used by mother Aeta on her first bath two to three weeks after giving birth to avoid relapse. The Aetas 
believe that they should wrap the newborn baby's umbilical cord in a cloth after it had detached from the baby.

If the child feels uncomfortable and cries the whole night or if it has burning fever, they consult the quack doctor. At night, they burn rubber outside their houses to drive away evil spirits which might be disturbing the baby. When the child had his first haircut, the mother placed the cut hair in the book or even inserted it in the pages of the book. It was done, so that the child will grow smart and well guided.

\section{Puberty and Adolescence}

Most of the beliefs and practices of the Aetas in this stage are not so much related to health care but more on cultural. Some of these are as follows:

Rites of Passage are practiced in most societies but it may vary how this rites are observed. Among aetas the rite of passage observed for males vary from that of females.

For the males, they practice rituals to welcome the newly circumcized aeta. One of these rituals is pintados practiced among aetas in order for the young man to be accepted in the tribe.

For the young women, they are asked to jump number of steps of their stairs in order not to have a longer number of days of menstruation. This is done during their first menstruation.

\section{Adulthood}

As noted, there was no single health care beliefs and practices noted in this stage of life among the Aetas in the rural communities. Though, there were some beliefs and practices noted but they were not related to health care.

\section{Old Age}

Death. They believe that they must not sweep the floor or take a bath as they mourn because it may cause illness or even death to another member of the family. They believe that if the person dreams about a falling tooth, a close relative will get sick and eventually would die; so, he must bite the bark of the first tree he sees as he wakes up to prevent a relative from dying. They also believe that the last will ask by a dying person should be done for if they will not, the spirit of that person will never be at peace and will haunt them that may cause fever or other illness to the living family members.

\section{Factors Affecting the Health Care Beliefs and Practices of the Aetas}

Modernization. The Aetas traditional beliefs are affected by modernizations like media and technology. It is said that the aetas are adaptive to their environment so it is not difficult to be accostumed to modernization. The aetas mentioned that their adaptivity is due to the fact that they are open to changes.

Media. Media is one of the factors affecting the health care beliefs and practices of Aetas. Young Aetas are interested in the latest trends. Publications have convinced the Aetas to follow the latest trends since they have also observed the changes around them. Aetas are nomadic in nature, that why it is not difficult for them to acquire some of these publications. 
The researchers have noticed that aside from printed publications, broadcast media had affected the health care beliefs and practices of Aetas. Televesions nowadays made aetas to try certain products or gadgets. Aetas easily get fascinated by the practices conveyed by the showbiz personalities.

Technology. Technology is said to be as application of knowledge. In this case, technology had contributed changes in the health care beliefs and practices of Aetas in rural communities.Aetas are already informed of the modern technology like cellular phones and television.

\section{Conclusion}

Not all health care beliefs and practices of Aetas were retained up to this time. The beliefs of Aetas regarding conception and pregnancy have been reversed as time goes by.

Pregnancy among Aetas is the period where most of health care beliefs and practices were observed. Some of their beliefs regarding child birth are changed when they penetrate the downstream. They do not practice the traditional way of giving birth.

Due to the effects of modernization and information taken from the sources such as media and technology, Aetas have lost some of their tribal practices. One of the practices lost over time was their traditional way of rite of passage.

The marriage rite was also different now a days for Aetas. They also followed the Catholic way of marriage.

Lastly, some Aetas' health care beliefs and practices regarding death and burial have been altered. These are affected by the entry of religious sisters and priests in their community.

Regardless of the fact that Aetas are still separated from mainstream to their secluded community, modernization such as media and technology still affected their beliefs and practices in general.

\section{References}

Catseye. (2004). The Negritos. Retrieved 4 March 2014 from http://www.camperspoint.com /The-Negritos.

Cordillera Schools Group. (2003). Ethnography of the major ethnolinguistic groups in the Cordillera. Quezon City, Philippines:New Day Publisher

Liu, F. \& Maitlis, S. (2010). Nonparticipant observation. In Encyclopedia of case study research (Vol. 1, pp. 611). Retrieved from http://www.sagereference.com/view/casestudy/n229.xml?hidePageNum\&print

McMillan, J. H., \& Schumacher, S. (2001). Research in education: A conceptual introduction. New York: Longman.

Seitz, Stefan. (2005). The aeta at the Mt. Pinatubo, Philippines: A minority group coping with disaster. Quezon City, Philippines:New Day Publisher

Wee, D. (No Date). Aeta. Retrieved 6 January 2014 from http://litera1 no4.tripod.com/aeta_frame.html 